\title{
A segmental osteotomy with 3D virtual planning to move a malpositioned dental implant
}

\author{
Dario Andrés Bastidas ${ }^{1,2^{*}}$ (D) Lina Roldan², Pamela Ramirez ${ }^{1}$ and Andrés Munera ${ }^{3}$
}

\begin{abstract}
Background: Correct positioning and alignment of dental implants are crucial to successfully meet the aesthetic and functional criteria in implant-prosthetic rehabilitation. When an implant is in the wrong position, especially in the esthetical zone, there are limited options to solve it. Some techniques have been described to reposition implants, such as reverse torque, trephine drills, and segmental osteotomies; current approaches aim to reduce the damage of the periimplant tissues.

Case presentation: A 20-year-old man with good general health was referred to the oral and maxillofacial surgery department of the CES University, Medellin Colombia in 2017, He had undergone a previous camouflage orthodontic therapy for a dental Class III, which finished in 2014, posteriorly a dental implant was placed in 2015 to replace upper right lateral incisor (1.2) before vertical growth of maxilla was complete; therefore, the implant was retained in a coronal position. A segmental osteotomy was suggested to reposition the implant in a more caudal position, a 3D surgical cut guide obtained by virtual planning was used to increase osteotomy accuracy and lower human error, to avoid the risk of damaging the adjacent tissues and to achieve a predictable result.
\end{abstract}

Conclusions: The segmental alveolar osteotomy is an effective alternative to reposition an implant; however, it must be carefully planned because human error remains a possibility that may affect the final result. Therefore, 3D planning is a better way to minimize these mistakes during the surgical procedure and the final position of the implant.

Keywords: Dental implant, Anterior segmental osteotomy, 3D planning, Computer-aided design (CAD), Computeraided manufacturing (CAM)

\section{Introduction}

Correct positioning and alignment of dental implants are crucial factors in achieving satisfactory aesthetic and functional results. However, some implants, for many reasons, may be mispositioned, or sometimes in growing patients at early stages of life. To correct that position, there are several options, such as prosthetic compensation, replacement, or transfer of the position of the implant $[1,2]$, and if prosthetic corrections are not

\footnotetext{
* Correspondence: ab@drandresb.com

${ }^{1}$ Department of Maxillofacial Surgery, University CES, Medellin, Colombia

${ }^{2}$ Department of Orthodontic, University CES, Medellin, Colombia

Full list of author information is available at the end of the article
}

sufficient, the malposition implant can be left alone under the soft tissue or submerged completely into the bone. Another option is to remove the implant [3, 4]. However, in the anterior zone of the maxilla known as the "aesthetic zone" implant removal frequently results in hard and soft tissue defects requiring corrections with advanced tissue regeneration procedures before inserting a new implant [5].

Dental implants with the wrong position have been treated through segmental alveolar osteotomies [6,7]. This technique had been initially used to treat ankylosed maxillary canines and to close one-tooth diastemas [8]. It has been described in some case reports in the

\section{Springer Open}

(0) The Author(s). 2021 Open Access This article is licensed under a Creative Commons Attribution 4.0 International License, which permits use, sharing, adaptation, distribution and reproduction in any medium or format, as long as you give appropriate credit to the original author(s) and the source, provide a link to the Creative Commons licence, and indicate if changes were made. The images or other third party material in this article are included in the article's Creative Commons licence, unless indicated otherwise in a credit line to the material. If material is not included in the article's Creative Commons licence and your intended use is not permitted by statutory regulation or exceeds the permitted use, you will need to obtain permission directly from the copyright holder. To view a copy of this licence, visit http://creativecommons.org/licenses/by/4.0/. 
literature with some variations to each technique. The basic concept is to move a bone-implant block, which is immediately stabilized in the new position by rigid fixation [6, 7, 9-20]. Besides, this bone-implant block could have a gradual movement if applying orthodontic forces or protocols of distraction osteogenesis [15, 17, 21, 22].

When the patient is still growing, there is an inferior displacement of the anterior maxilla approximately 1.2 $\mathrm{mm} /$ year, resulting in disharmony of oral implants in the anterior zone when compared to the natural teeth final position. On the other hand, during adolescence, the maxillary molars and incisors erupt 1.2 to $0.9 \mathrm{~mm} /$ year [23]. Those factors must be considered when evaluating the possibility to use dental implants at early ages. Vertical growth of the maxilla continues until at 17 or 18 years for girls and even later for boys. However, between the ages of 15 to 25 , the teeth can move an amount of $5 \mathrm{~mm}$ vertically [24].

\section{Case report}

A 20-year-old man with good general health was referred to the oral and maxillofacial surgery department of the CES University, Medellin, Colombia in 2017, He had undergone a previous camouflage orthodontic therapy for a dental Class III, which finished in 2014, posteriorly the patient had a dentoalveolar trauma resulting in avulsion of the upper right lateral incisor (1.2) and required a dental implant in 2015 to replace it. Those therapies were done in another institution; therefore all of the information on the previous procedures and supplies used was not fully known. Nonetheless, it was possible to recover some information on the implant, it was a tapered implant with $3.5 \mathrm{~mm}$ diameter and $12 \mathrm{~mm}$ length and internal hexagonal conexion. On clinical examination, the patient presented with a skeletal and dental Class III due to maxillary hypoplasia and a prognathic mandible, anterior crossbite and open bite, lingualized lower incisors, the mentioned dental implant, and multiple attritions in the molars occlusal surface (Fig. 1).

The treatment plan suggested for this patient was orthognathic surgery with surgery first protocol, orthodontic treatment, and a segmental osteotomy to move the dental implant to a caudal position once the orthodontic treatment was finished; the occlusal surfaces of molars and premolars were restored to get aestheticfunctional rehabilitation of the occlusal plane using posterior resin $\left(\mathrm{P} 70-3 \mathrm{M}^{\mathrm{mm}}\right.$ resin). Orthodontic treatment was performed with conventional $0.018 \times 0.025$ inches braces. Leveling and alignment began with 0.014 inches nickel-titanium arch-wire, followed by $0.016,0.016 \times$ 0.016. During the first arch-wires, anteroinferior teeth were not included in the arch. The occlusal plane was restored, and then $0.016 \times 0.016$ inches nickel-titanium arch-wires were placed, followed by $0.016 \times 0.022$, finally, stainless steel $0.016 \times 0.022$ inches rectangular arch-wires were used for the orthodontic finishing stage. The upper right lateral incisor (1.2 implant) was never included in the orthodontic treatment (Fig. 2).

When the orthodontic treatment was finished, 3D planning for the alveolar osteotomy to reposition the implant was performed. Digital Imaging and Communication on Medicine (DICOM) and Standard Triangle Language (STL) were used to create the surgical guide, and those files were processed in a 3D software (NemoStudio 2018 version, Spain) to build a surgical guide, which had 3 cuts, on the top, mesial, and distal areas of the implant (Fig. 3).
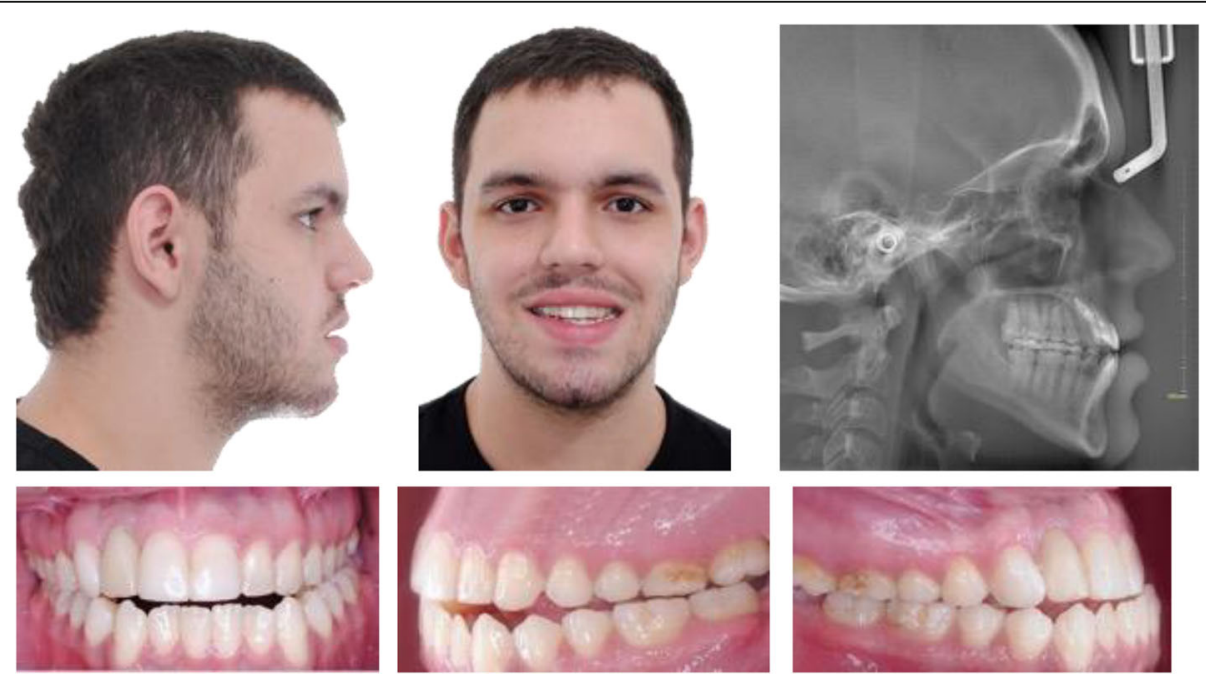

Fig. 1 Pre-treatment extra-oral and intra-oral photos, and lateral cephalic X-ray 

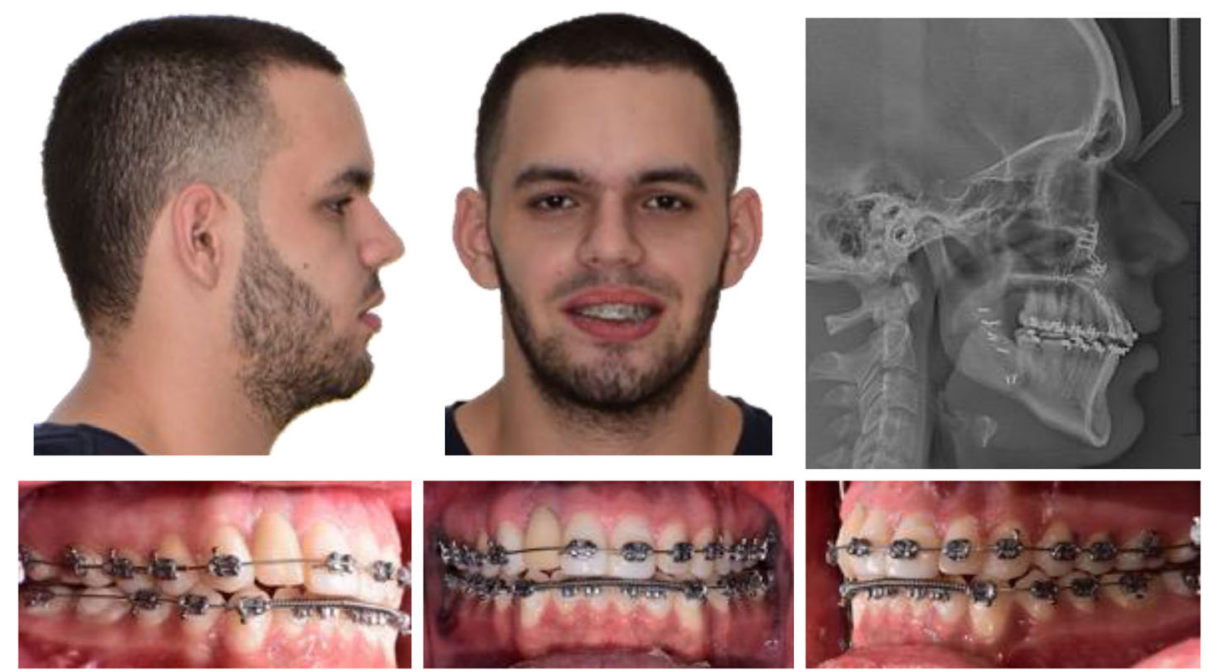

Fig. 2 Extra-oral and intra-oral photos, and lateral cephalic X-ray during treatment

\section{Surgical procedure}

It was performed under local anesthesia (Lidocaine 2\% with epinephrine 1:80.000). The access was achieved with a horizontal incision, coronal to the mucogingival line to maintain the marginal gingival harmony, tunnel dissection down to the alveolar crest, and upper to the nasal notch. After stabilization of the surgical guide with the contiguous teeth, the osteotomy was performed using Piezotome tips of $0.1 \mathrm{~mm}$ thickness (Piezotome Solo LED, Acteon, France, Tip reference 602990/1 and $602965 / 1$ ), aiming to preserve the palatal soft tissue and allow it to join the coronal movement of the bone segment; the osteotomy was then finished with osteotomes. The ceramic crown was cut and polished until a similar height to the contralateral incisor was achieved, the osteotomy segment was mobilized, and the new position was stabilized with a miniplate and a screw of $1.2 \mathrm{~mm}$ osteosynthesis system (Mondeal). The osteotomy's gap was 7 $\mathrm{mm}$, and it was filled in with pulverized bone graft (Puros ${ }^{\circ}$ Cancellous Particulate Allograft). A connective tissue graft was placed under the keratinized gum, and it was fixed to the orthodontic arch-wire using suture suspension in order to improve the thickness of the gingiva. Closing of the wound was done with non-absorbable monofilament nylon 6.0 (Fig. 4).

Finally, after 4 weeks of the surgical procedure, a passive bracket was adhered on the buccal surface of the 1.2 implant crown, and the finishing stage of the orthodontic treatment started 2 weeks after that. The braces were removed 6 months later to allow the gum and the bone regeneration to stabilize; at this point, the zenith of the upper right lateral incisor was at the same level as the contralateral incisor (Fig. 5). Once this treatment was finished, the patient was redirected to the prosthodontics department to change the definitive crown restoration.
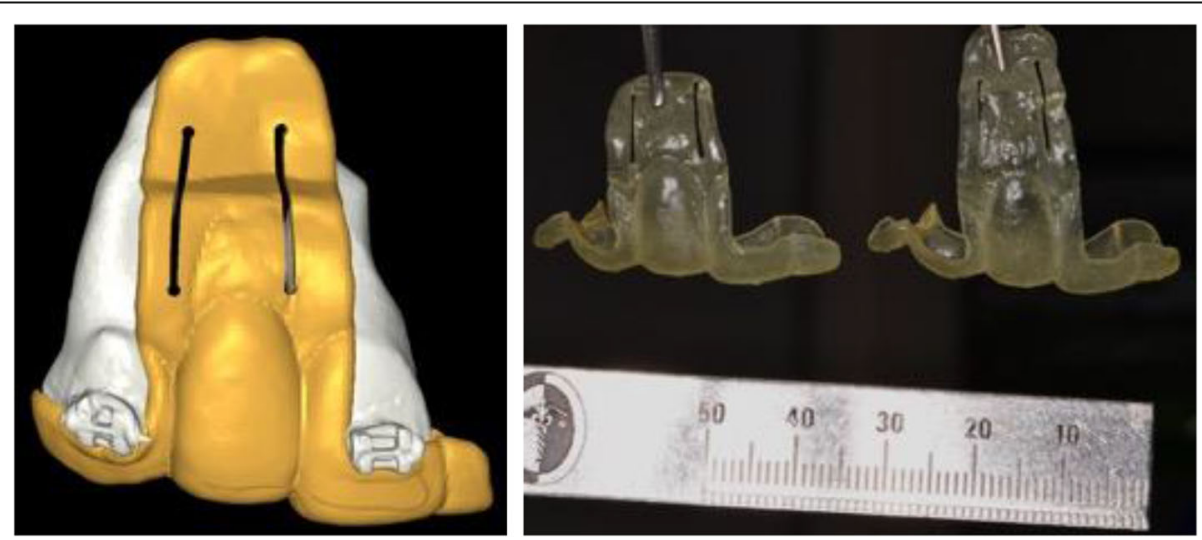

Fig. 3 Surgical guide for segmentary osteotomy 

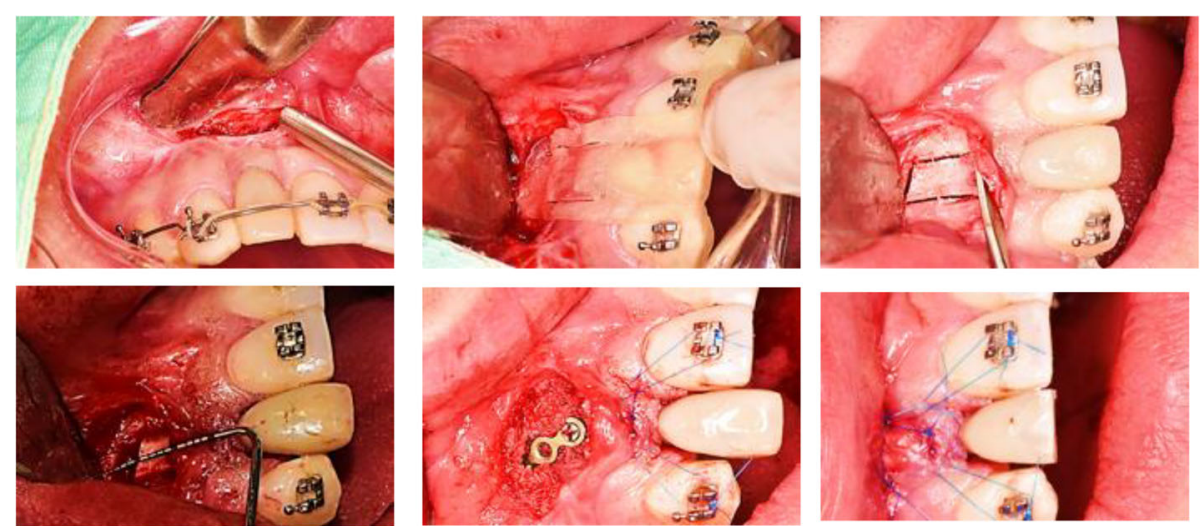

Fig. 4 Surgical procedure

\section{Discussion}

Dental implant in the aesthetic area can be tricky, and there are several factors, such as lack of surgical planning, surgical guide inaccuracies, inexperience, and wrong placement in the insertion of the implant, all of which can result in osseointegrated implants placed in non-optimal positions that lead to poor prosthetic restoration. These factors must be evaluated before treatment to aim for a successful result $[25,26]$. This matter could also affect growing patients since the vertical growth of the maxilla continues up until 25 years [23, 24], because of that, clinicians ought not to put osteointegration implants before this age. One alternative to the growing patient to maintain bone level and allow the use of a temporary fixed crown is mini-screws [27].

When the malposition of a dental implant is considered mild, it can be corrected by prosthetic modifications, such as the use of custom-made abutments, angled implant abutments, and methods of cementation of the prosthetic device rather than screw systems; however, when malposition is severe, it is necessary to perform an intervention directly on the implant [12, 19]. Removal of an osseointegrated implant usually requires invasive surgery and damage to the surrounding bone; Roy et al. reported in 2020 [5], the principal reasons for implant removal are periimplantitis and crestal bone
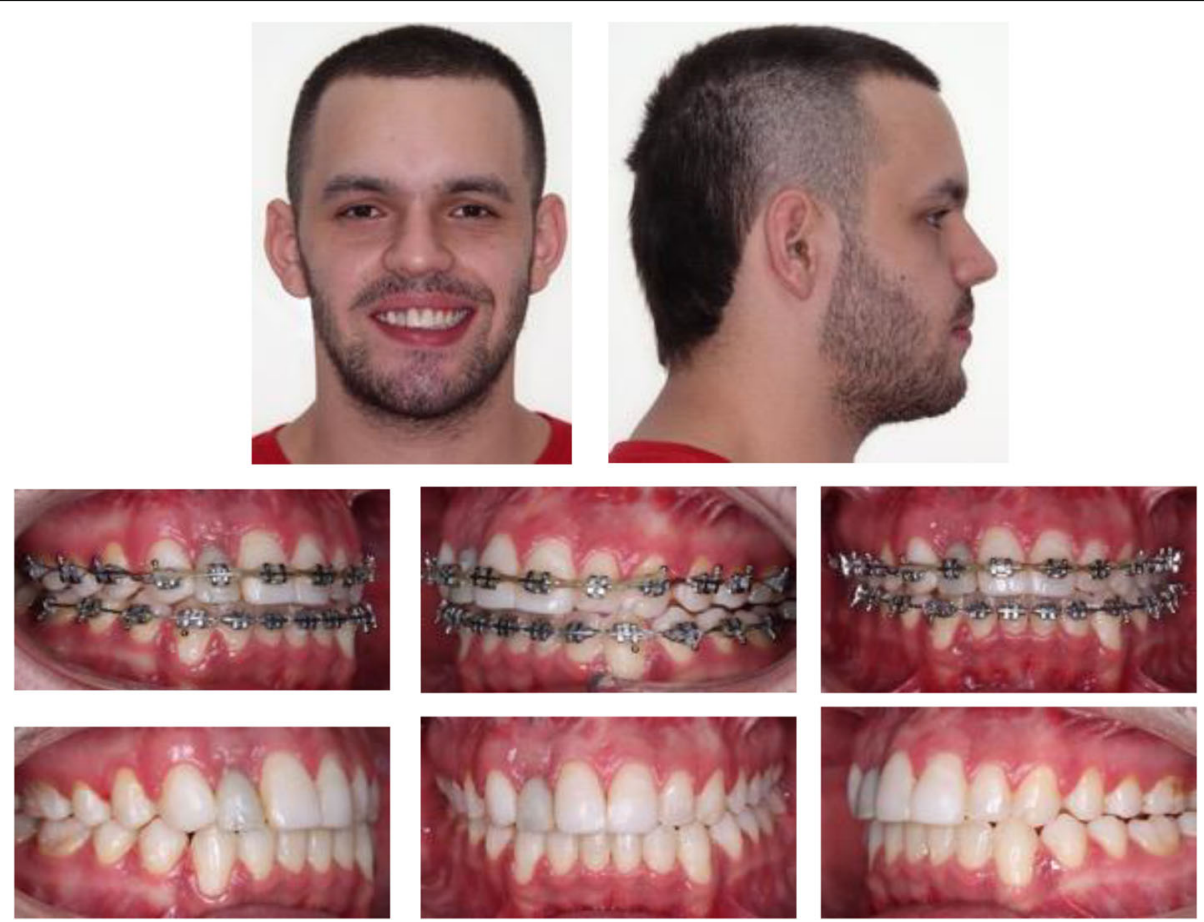

Fig. 5 Finishing stage of orthodontic treatment 
loss, mispositioning only accounts for a $8.4 \%$; some commonly used approaches for implant removal are reverse torque and trephine drills, reverse torque being not only the principal but also the most conservative approach requiring removal of little to no bone, trephine drills were indicated when torque values exceeded $200 \mathrm{~N} / \mathrm{cm}$; however, some of the reverse torque techniques described the need to use a trephine drill in the coronal aspect of the implant to ease the explantation, in addition, the success rate for reverse torque was only of $87.7 \%$; it is also important to address immediate implant placement, in the mentioned study it was only possible in $22.3 \%$ of the cases among all presented techniques [5]. Due to the unpredictability of these procedures on the amount of bone left after surgery, some patients must undergo several surgical procedures that may often be necessary to complete a satisfactory result, such as bone a soft tissue augmentation before considering a new implant placement; also, all these procedures can present high costs for the patient and lengthen in total treatment time [5]. Segmental osteotomy has been described in some case reports as an additional alternative to relocate a mispositioned implant without the need to remove the implant itself, aiming for preservation of already achieved osteointegration and bone architecture and to lower the risk to require additional procedures before new implant positioning can be done $[3,6,7,9-14,16-$ $20,22]$. Nowadays, technology is an ally, making possible to plan all types of osteotomies which minimize error during surgical procedure; besides, the new implant position can also be planned to achieve a proper restoration. Stacchi et al. reported a case back in 2012 [12] using CBCT for a segmental osteotomy planning, from which he obtained a stereolithographic model of the maxillary bone and was then replicated in a stone cast model were the surgery was manually planned to further design a titanium guide to reposition the bone block including the implant; nonetheless, the osteotomies were not virtually planned and this can still provide some level of error during surgical procedure that can cause failure of the repositioning, which is why, in this paper, a surgical guide for the osteotomies was designed using 3D virtual planning, in order to reduce human error [12].

There are similar principles in cases reported in the literature, such as the vestibular approach always be the election of incision, preservation of the palatal or lingual vascular supply, care to avoid damage to adjacent natural teeth, and rigid fixation of the bone block [7]. Stacchi et al. suggested three fundamental factors to alveolar osteotomy for implants, maximum preservation of blood supply during the early phases of healing, minimum gap between the mobilized block and adjacent bone, firm and stable bone block fixation [7]. On the other hand, the absence of micromovements is a fundamental element in promoting osseous repair, because the absence of stability of the osteotomized segment can result in non-union or malunion of the bone fragment $[28,29]$. The issue is the grand amount of differences in described techniques, from the osteotomy planning to the relocation of the bone segment; some authors even consider the approach of a distraction osteogenesis driven by orthodontic treatment, thus making difficult to unify techniques and therefore to analyze success rate and best approach.

\section{Conclusions}

The segmental alveolar osteotomy is an effective alternative to reposition an implant; however, it must be carefully planned because human error remains a possibility that may alter the final result. Therefore, 3D planning is a better way to minimize these mistakes during the surgical procedure and final position of the implant. More studies, greater patient samples, and longer follow-up time are needed to define the technique that can lead to a higher success rate and reduce damage to periimplantar tissues.

\section{Abbreviations \\ DICOM: Digital Imaging and Communication on Medicine; STL: Standard Triangle Language}

Acknowledgements

Not applicable.

Authors' contributions

All authors read and approved the final manuscript.

Funding

The authors received no financial support for the research, authorship, and publication of this article.

Availability of data and materials Not applicable.

\section{Declarations}

Ethics approval and consent to participate

The patient has given his consent to publish his photos in a scientific journal.

Consent for publication

The authors give their consent for its publication.

\section{Competing interests}

The authors declared no potential conflicts of interest with respect to the research, authorship, and publication of this article.

\section{Author details}

${ }^{1}$ Department of Maxillofacial Surgery, University CES, Medellin, Colombia.

${ }^{2}$ Department of Orthodontic, University CES, Medellin, Colombia.

${ }^{3}$ Department of Prosthodontics, University CES, Medellin, Colombia. 
Received: 22 February 2021 Accepted: 28 May 2021

Published online: 12 August 2021

\section{References}

1. Higginbottom F, Belser U, Jones JD, Keith SE. Prosthetic management of implants in the esthetic zone. Int J Oral Maxillofac Implants. 2004;19(Suppl): 62-72.

2. Grunder U, Gracis S, Capelli M. Influence of the 3-D bone-to-implant relationship on esthetics. Int J Periodontics Restorative Dent. 2005; 25(2):113-9.

3. Samborski CS. Management of an implant case that required retreatment: a case report. J Oral Implantol. 2001;27(3):118-22. https://doi.org/10.1563/154 8-1336(2001)027<0118:MOAICT>2.3.CO;2.

4. Fugazzotto PA. Bone regeneration over a poorly-positioned implant to correct an esthetic deformity: a case report. J Periodontol. 1993;64(11):108891. https://doi.org/10.1902/jop.1993.64.11.1088.

5. Roy M, Loutan L, Garavaglia G, Hashim D. Removal of osseointegrated dental implants: a systematic review of explantation techniques. Clin Oral Investig. 2020;24(1):47-60.

6. Kassolis JD, Baer ML, Reynolds MA. The segmental osteotomy in the management of malposed implants: a case report and literature review. J Periodontol. 2003;74(4):529-36. https://doi.org/10.1902/jop.2003.74.4.529.

7. Stacchi C, Chen ST, Raghoebar GM, Rosen D, Poggio CE, Ronda M, et al. Malpositioned osseointegrated implants relocated with segmental osteotomies: a retrospective analysis of a multicenter case series with a 1to 15-year follow-up. Clin Implant Dent Relat Res. 2013;15(6):836-46. https:// doi.org/10.1111/j.1708-8208.2012.00444.x.

8. Patrikiou AK, Katsavrias EG. Repositioning ankylosed maxillary canines by segmental osteotomy. J Clin Orthod JCO. 1995;29(10):625-8.

9. Svensson B, Adell R, Swartz B. Correction of implant malalignment by segmental osteotomy: a case report. Int J Oral Maxillofac Implants. 1993;8(4): 459-63.

10. Martin RJ, Goupil MT, Goldschmidt M. Single-implant segmental osteotomy: a case report. Int J Oral Maxillofac Implants. 1998;13(5):710-2.

11. Guerrero CA, Laplana R, Figueredo N, Rojas A. Surgical implant repositioning: a clinical report. Int J Oral Maxillofac Implants. 1999; 14(1):48-54

12. Stacchi C, Bonino M, Di Lenarda R. Surgical relocation of a malpositioned, unserviceable implant protruding into the maxillary sinus cavity. A clinical report. J Oral Implantol. 2012;38(4):417-23. https://doi.org/10.1563/AAID-JOID-10-00107.

13. Storum K, Carrick JL. Implant-osseous osteotomy for correction of the misaligned anterior maxillary implant. Dent Clin North Am. 2001:45(1):181-7.

14. Poggio CE, Salvato A. Implant repositioning for esthetic reasons: a clinical report. J Prosthet Dent. 2001;86(2):126-9. https://doi.org/10.1067/mpr.2 001.117054

15. Zechner W, Bernhart T, Zauza K, Celar A, Watzek G. Multidimensional osteodistraction for correction of implant malposition in edentulous segments. Clin Oral Implants Res. 2001;12(5):531-8. https://doi.org/10.1034/ j.1600-0501.2001.120515.x.

16. Parma-Benfenati S, Maino GB. Combined Piezosurgery and Selective Distraction Osteogenesis to Correct Malpositioned Implants: A Case Report. Restorative Dent. 2015;35(2):8.

17. Gotta S, Sarnachiaro GO, Tarnow DP. Distraction osteogenesis and orthodontic therapy in the treatment of malpositioned osseointegrated implants: a case report. Pract Proced Aesthetic Dent PPAD. 2008;20(7):401-5.

18. da Silva ALF, Borba AM, Bandeca MC, Volpato LER, Porto AN, Freitas DL, et al. Modified Segmental Osteotomy for Relocation of Malpositioned Implant: Case Report. J Int Oral Health JIOH. agosto de. 2015;7(8):134-7.

19. Hallman M, Carlsson B. Surgical correction of malpositioned implants. A case report. Clin Oral Implants Res. 1996;7(4):316-9. https://doi.org/10.1034/ j.1600-0501.1996.070403.x.

20. Warden PJ, Scuba JR. Surgical repositioning of a malposed, unserviceable implant: case report. J Oral Maxillofac Surg Off J Am Assoc Oral Maxillofac Surg. 2000;58(4):433-5. https://doi.org/10.1016/S0278-2391(00)90930-3.

21. Ueki K, Marukawa K, Okabe K, Moroi A, Nakagawa K, Yamamoto E, et al. Esthetic improvement using conventional orthodontic devices after segmental osteotomy in treatment of malpositioned implants. J Oral Maxillofac Surg Off J Am Assoc Oral Maxillofac Surg. 2011;69(3):939-43. https://doi.org/10.1016/j.joms.2010.07.045.
22. Oduncuoglu BF, Alaaddinoglu EE, Oguz Y, Uckan S, Erkut S. Repositioning a prosthetically unfavorable implant by vertical distraction osteogenesis. J Oral Maxillofac Surg Off J Am Assoc Oral Maxillofac Surg. 2011;69(6):1628-32. https://doi.org/10.1016/j.joms.2010.12.025.

23. Buschang P, Roldan S, Tadlock L. Guidelines for assessing the growth and development of orthodontic patients. Semin Orthod. 2017;23(4):321-5. https://doi.org/10.1053/j.sodo.2017.07.001.

24. Heij DGO, Opdebeeck H, van Steenberghe D, Kokich VG, Belser U, Quirynen M. Facial development, continuous tooth eruption, and mesial drift as compromising factors for implant placement. Int J Oral Maxillofac Implants. 2006:21(6):867-78

25. Chen ST, Darby IB, Reynolds EC. A prospective clinical study of nonsubmerged immediate implants: clinical outcomes and esthetic results. Clin Oral Implants Res. 2007;18(5):552-62. https://doi.org/10.1111/j.1600-0501.2 007.01388.x.

26. Buser D, Chen ST, Weber HP, Belser UC. Early implant placement following single-tooth extraction in the esthetic zone: biologic rationale and surgical procedures. Int J Periodontics Restorative Dent. 2008;28(5):441-51.

27. Cope JB, McFadden D. Temporary replacement of missing maxillary lateral incisors with orthodontic miniscrew implants in growing patients: rationale, clinical technique, and long-term results. J Orthod. 2014;41(Suppl 1):s62-74. https://doi.org/10.1179/1465313314Y.0000000112.

28. Bays RA. Rigid stabilization system for maxillary osteotomies. J Oral Maxillofac Surg Off J Am Assoc Oral Maxillofac Surg. 1985;43(1):60-3. https:// doi.org/10.1016/S0278-2391(85)80017-3.

29. Johnson EE, Urist MR, Finerman GA. Distal metaphyseal tibial nonunion Deformity and bone loss treated by open reduction, internal fixation, and human bone morphogenetic protein (hBMP). Clin Orthop Relat Res. 1990; (250):234-40.

\section{Publisher's Note}

Springer Nature remains neutral with regard to jurisdictional claims in published maps and institutional affiliations.

\section{Submit your manuscript to a SpringerOpen ${ }^{\circ}$ journal and benefit from:}

- Convenient online submission

- Rigorous peer review

- Open access: articles freely available online

High visibility within the field

- Retaining the copyright to your article

Submit your next manuscript at $>$ springeropen.com 